\title{
Distribution characteristics and indicator significance of Dechloranes in multi-matrices at Ny-Ålesund in the Arctic
}

\author{
Guangshui $\mathrm{Na}^{1,2, *}$, Wei Wei ${ }^{1,3}$, Shiyao Zhou ${ }^{5}$, Hui Gao ${ }^{1}$, Xindong $\mathrm{Ma}^{1}$, Lina Qiu ${ }^{1,4}$, \\ Linke $\mathrm{Ge}^{1}$, Chenguang $\mathrm{Bao}^{1}$, Ziwei $\mathrm{Yao}^{1}$
}

1. Key Laboratory for Ecological Environment in Coastal Areas, National Marine Environmental Monitoring Center, Dalian 116023, China

2. Research Center for Eco-environmental Sciences, Chinese Academy of Sciences, Beijing 100085, China

3. School of Chemistry and Chemical Engineering, Liaoning Normal University, Dalian 116029, China

4. School of Biological Technology, Dalian Polytechnic University, Dalian 116034, China

5. Dalian Institute of Science \& Technology, Dalian 116052, China

\section{A R T I C L E I N F O}

Article history:

Received 28 March 2014

Revised 20 July 2014

Accepted 21 July 2014

Available online 15 November 2014

Keywords:

Dechloranes

Arctic

Multi-matrices

Distribution characteristic

Ratio

Source analysis

\begin{abstract}
A B S T R A C T
In recent years, Dechloranes have been widely detected in the environment around the world. However, understanding and knowledge of Dechloranes in remote regions, such as the Arctic, remain lacking. Therefore, the concentrations of 5 Dechloranes in surface seawater, sediment, soil, moss, and dung collected from Ny-Ålesund in the Arctic were measured with the concentrations $93 \mathrm{pg} / \mathrm{L}, 342,325,1.4$, and $258 \mathrm{pg} / \mathrm{g}$, respectively, which were much lower than those in Asian and European regions. The mean ratios of anti-Dechlorane Plus (DP) to total DP $\left(f_{\text {anti }}\right)$ in seawater, sediment, soil, moss, dung, and atmospheric samples were $0.36,0.21,0.18$, $0.27,0.66$, and 0.43 , respectively. Results suggested that the main source of DP in seawater, sediment, soil, and moss was long-range atmospheric transport. However, the ratio identified in dung was different, for which the migration behavior of the organism is probably the main source of DP.
\end{abstract}

(C) 2014 The Research Center for Eco-Environmental Sciences, Chinese Academy of Sciences. Published by Elsevier B.V.

\section{Introduction}

Halogenated (usually brominated or chlorinated) flame retardants are chemicals that are extensively used in consumer products, including electronic equipment, textiles, furniture, and automobiles, to improve their resistance to fire (Guerra et al., 2011). Dechloranes (Decs), as highly chlorinated flame retardants, were reported to have flame-retardant properties similar to that of mirex. Decs, developed by Hooker Chemicals and Plastics (now known as OxyChem), partially replaced mirex for non-agricultural applications after use of the latter was restricted during the 1970s because of its toxicity (INCHEM, 2010). Decs include Dec 602 $\left(\mathrm{C}_{14} \mathrm{H}_{4} \mathrm{Cl}_{12} \mathrm{O}\right)$, Dec $603\left(\mathrm{C}_{17} \mathrm{H}_{8} \mathrm{Cl}_{12}\right)$, Dec $604\left(\mathrm{C}_{13} \mathrm{H}_{4} \mathrm{Br}_{4} \mathrm{Cl}_{6}\right)$, and
Dechlorane Plus (DP, $\mathrm{C}_{18} \mathrm{H}_{12} \mathrm{Cl}_{12}$, also called as Dechlorane 605). These substances are hexachlorocyclopentadiene Diels-Alder adducts that contain a basic bicyclo[2,2,1]-heptene structure (Milne, 2005). Dec 602 is used in fiberglass-reinforced nylon- 6 at $18 \%$ by weight (Chanada and Roy, 2007). Dec 604 is used in Molykote AS-810 silicone grease (10\% to 30\%) produced by Dow Corning USA to lubricate metal-to-metal and metal-to-plastic substrates in electro-mechanical applications (MatWeb, 2009). Dec 604 has also been reported as an impurity (2\%) in a commercial product of mirex (NTP, 1990). DP is used as a flame retardant in electrical hard plastic connectors in television and computer monitors, wire coating, and furniture (Betts et al., 2006). Technical DP mixture is composed primarily of two isomers, the

\footnotetext{
* Corresponding author. E-mail: gsna@nmenmc.gov.cn (Guangshui Na).
} 
syn- and anti-isomers. The different physical and chemical properties of DP isomers can lead to dissimilar persistence in the environment (Hoh et al., 2006; Zhu et al., 2007).

Decs have become a ubiquitous contaminant in the environment. Accordingly, environmental concerns have emerged because of the widespread detection and persistence of Decs in the environment and their bioaccumulation in biota (Feo et al., 2012; Xian et al., 2011). Decs 602, 603, and 604 were detected in sediments and fish (Jia et al., 2011; Qiu et al., 2007; Sverko et al., 2010). DP was detected in various environmental matrices, including air (Ren et al., 2008; Wang et al., 2010b), indoor dust (Zhu et al., 2007), water (Möller et al., 2010), soil (Ma et al., 2011), sediments (Sverko et al., 2010; Qiu et al., 2007), plants (Chen et al., 2011; Qiu and Hites, 2008), biota (Sverko et al., 2010; Tomy et al., 2007; Wu et al., 2010; Zhang et al., 2011), and human serum (Ren et al., 2009), in North America, Europe, and China.

Information on the environmental occurrence, fate, and behavior of Decs is still limited. Most studies on Decs have been conducted near manufacturing areas. However, Decs are bio-accumulative, persistent, and can undergo long-range atmospheric transport. There is evidence that Decs are emitted by several means into the environment, and are even transported into remote regions, including the North and South Poles as well the Qinghai-Tibet Plateau area. Ny-Ålesund is one of the northernmost human settlements in the world. It is situated in Kongsfjorden, an inlet on the west coast of Spitsbergen, which is the largest of the Svalbard Islands. Most of the animal and plant species in the islands have been identified in Spitsbergen, making the town an optimal base to conduct Arctic research. Thus, the settlement was chosen as the study area in this research. The objective of this study is to provide the levels of Decs in multi-matrices in Ny-Ålesund to analyze the source of this flame retardant in the Arctic area by using the isomer ratio profiles of DP in environmental matrices.

\section{Materials and methods}

\subsection{Sampling and preparation}

Concurrent surface seawater and sediment sampling was conducted in King's Bay. Surface soil (upper $5 \mathrm{~cm}$ ), moss, and reindeer dung were simultaneously collected. Atmospheric samples in the gaseous phase were collected using polyurethane foam. Particle-bound analytes in air were collected on a quartz fiber filter in July 2012 in the Ny-Ålesund area $\left(78^{\circ} 55^{\prime} \mathrm{N}\right.$, $\left.11^{\circ} 56^{\prime} \mathrm{E}\right)$, Svalbard in the Arctic Circle (Fig. 1). Only damp-dry dung was collected to reduce the influence of secondary Decs input/loss after excretion. The average temperature during sampling was $5^{\circ} \mathrm{C}$. All samples were kept in aluminum foil and stored at $-20^{\circ} \mathrm{C}$ after sampling. Soil, sediment, moss, and reindeer dung samples were freeze-dried, ground, and sieved (80 mesh) prior to analysis.

\subsection{Materials}

Dec 602 (95\%), Dec 603 (98\%), and Dec 604 (95\%) were purchased from Toronto Research Chemical Inc. (Toronto Research Chemical Inc., Ontario, Canada). A standard mixture of DP, which contained syn- and anti-DP, was obtained from AccuStandard, Inc. (AccuStandard Inc., Connecticut, USA). Meanwhile, the internal standard of polychlorinated biphenyl 209 (99\%) was acquired from J\&K Scientific Ltd. (Beijing, China). All organic solvents used in the study (dichloromethane, n-hexane) were pesticide grade. Water was purified by a Milli-Q system. Silica, neutral alumina, and anhydrous sodium sulfate were purchased from Merck (Darmstadt, Germany).

\subsection{Extraction, cleanup, and analysis}

Approximately $5 \mathrm{~g}$ sediment, soil, moss, and dung (reindeer and bird) samples mixed with the surrogate standard were extracted via accelerated solvent extraction with $50 \mathrm{~mL}$ hexane/dichloromethane (DCM) (1:1, V/V). Activated copper powder was added to the extracts of sediment and soil to remove elemental sulfur. The seawater samples, C18 and glass fiber filter (GFF), were extracted and analyzed separately to obtain information on their respective water and particle phases. Approximately 8.0 L surface seawater samples were collected by C18 (the water phase) and GFF (the particle phase) at each station, and the C18 and GFF samples were soaked for $12 \mathrm{hr}$ with $50 \mathrm{~mL}$ hexane/DCM (1:1, V/V) and were extracted in an ultrasonic bath for $30 \mathrm{~min}$. The procedure was repeated twice. Air samples were collected by a high-volume air sampler (HiVol) equipped with GFF to capture particles and a PUF plug for the gas Decs. The HiVol operated at an average flow rate of $1.0 \mathrm{~m}^{3} / \mathrm{min}$ and the total sampled air volume averaged about $2880 \mathrm{~m}^{3}$. These samples were Soxhlet-extracted for $24 \mathrm{hr}$ using hexane/DCM (1:1, V/V). The raw extracts of all samples were evaporated to $5 \mathrm{~mL}$ with a rotary evaporator and were transferred to a multi-layer column filled from the bottom with $2 \mathrm{~g}$ activated silica gel, $4 \mathrm{~g}$ neutral alumina, and $1 \mathrm{~cm}$ anhydrous $\mathrm{Na}_{2} \mathrm{SO}_{4}$ (pre-soaked in hexane). The extracts were then eluted with $70 \mathrm{~mL}$ hexane/DCM $(1: 1, \mathrm{~V} / \mathrm{V})$ mixture and were further evaporated under a gentle $\mathrm{N}_{2}$ stream. The sample was solvent-exchanged to hexane $(500 \mu \mathrm{L})$.

Decs were analyzed on an Agilent 6890 N gas chromatograph coupled with a 5973I mass spectrometer (MS, Agilent Technologies, Inc. Santa Clara, California, USA) using the negative chemical ionization mode with methane as the ionization gas fitted with a DB-5HT capillary column (0.25 mm i.d. $\times 30 \mathrm{~m} \times 0.10 \mu \mathrm{m}$ film thickness, J\&W Scientific, Inc., Santa Clara, California, USA). The injection volume was $1.0 \mu \mathrm{L}$ in the splitless mode. Helium was used as the carrier gas at a flow rate of $1.0 \mathrm{~mL} / \mathrm{min}$. The gas chromatography oven was programmed as follows: initial $80^{\circ} \mathrm{C}$ for $2 \mathrm{~min}$, ramped at $20^{\circ} \mathrm{C} / \mathrm{min}$ to $180^{\circ} \mathrm{C}$, then $5^{\circ} \mathrm{C} / \mathrm{min}$ to $250^{\circ} \mathrm{C}$ and held for $2 \mathrm{~min}$, then $30^{\circ} \mathrm{C} / \mathrm{min}$ to $310^{\circ} \mathrm{C}$ and held for a final $5 \mathrm{~min}$. The MS transfer line was held at $275^{\circ} \mathrm{C}$. The temperature of the ion source and the quadrupole was $150^{\circ} \mathrm{C}$. The instrument was operated in selected ion monitoring mode $(\mathrm{m} / \mathrm{z}$ 606.0, 608.2, and 610.0 for Dec 602; m/z 628.0, 630.0, and 634.0 for Dec 603; $\mathrm{m} / \mathrm{z}$ 569.0, 608.0, and 612.0 for Dec 604; $\mathrm{m} / \mathrm{z}$ 646.0, 645.0, and 649.0 for syn-DP and ant-DP).

\subsection{Quality control}

Different measures were performed to assess the accuracy and reliability of the obtained data. Field and laboratory blanks (method blanks) were extracted and analyzed in the same manner as field samples. The method detection limits (MDLs) were derived from mean blank values plus thrice the standard deviation; for compounds with no blank, from the 


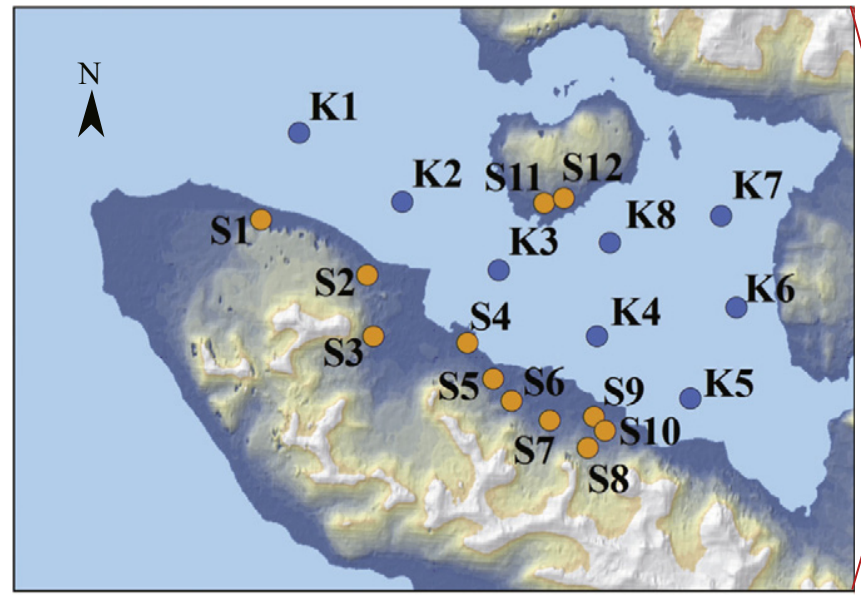

Soil sampling site

Sea water andsediment sampling site

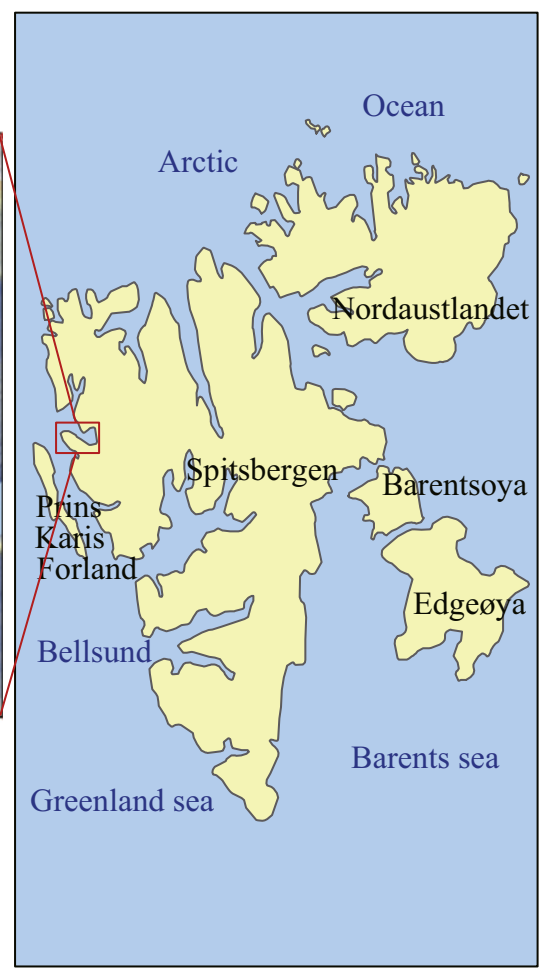

Fig. 1 - Sampling sites and the location of Ny-Ålesund, Svalbard in the Arctic Circle (K1-K8) are the stations of seawater and sediment samples, and S1-S12 are the sampling sites of soil, moss and dung.

instrumental detection limits at a signal-to-noise ratio $=3$. The MDLs of Decs ranged from 0.57 to $7.55 \mathrm{pg} / \mathrm{g}$ in sediment and soil samples, from 6.44 to $88.44 \mathrm{pg} / \mathrm{L}$ in seawater samples, from 4.08 to $54.43 \mathrm{pg} / \mathrm{g}$ in dung samples, and from 0.01 to $0.14 \mathrm{pg} / \mathrm{m}^{3}$ for atmospheric samples. The mean recoveries of the surrogates ranged from $80 \%$ to $113 \%$.

\section{Results and discussion}

\subsection{Distribution and characteristics of Decs in multi-matrices}

The minimum, maximum, and mean concentrations of 5 Decs ( $\sum$ Decs) and individual Decs in surface seawater, sediment, soil, moss, and dung samples are summarized in Table 1.

\subsubsection{Seawater and sediment concentrations}

$\sum$ Decs in surface seawater ranged from 69 to 303 pg/L (sum of dissolved and particulate phases). Among the 5 Decs, Dec 602 was not detected in any of the seawater samples and Dec 603 was detected in only $37.5 \%$ of the samples. Other Decs, including Dec 604, syn-DP, and anti-DP, were detected in all seawater samples from King's Bay. The seawater concentration of DP was significantly lower than that near the Great Lakes in America (with a mean of $6.24 \mathrm{ng} / \mathrm{L}$ ) (Venier et al., 2008). The rivers that have been studied in China are located in the relatively large cities of Dalian and Harbin, in which the DP levels are within the range of 0.2-2 ng/L (Jia et al., 2011; Ma et al., 2011; Qi et al., 2010; Wu et al., 2010). These concentrations are significantly higher than the concentrations obtained in this study.

Table 1 - Range and mean concentrations of 5 Decs ( $\sum$ Decs) and individual Decs in surface seawater (pg/L), sediment, soil, moss, and reindeer dung (pg/g dry weight) samples.

\begin{tabular}{|c|c|c|c|c|c|c|c|c|c|c|}
\hline \multirow[t]{2}{*}{ Decs } & \multicolumn{2}{|c|}{ Seawater } & \multicolumn{2}{|c|}{ Sediment } & \multicolumn{2}{|c|}{ Soil } & \multicolumn{2}{|c|}{ Moss } & \multicolumn{2}{|c|}{ Dung } \\
\hline & Mean & Range & Mean & Range & Mean & Range & Mean & Range & Mean & Range \\
\hline Dec 602 & - & nd & 0.7 & nd-1.4 & 0.7 & nd-2.8 & - & nd & 4.6 & nd-17 \\
\hline Dec 603 & 2.3 & nd-6.3 & 1.5 & $0.2-3.4$ & 2.6 & nd-8.6 & 0.1 & nd-0.9 & 2.5 & nd-5.5 \\
\hline Dec 604 & 53 & 25-106 & 7.9 & $1.9-20$ & 13 & $1.4-73$ & 0.2 & nd-0.4 & 69 & $12-142$ \\
\hline syn-DP & 61 & $22-116$ & 270 & $85-648$ & 284 & 94-1010 & 1.0 & $0.1-2.5$ & 87 & $3.5-369$ \\
\hline anti-DP & 32 & $13-88$ & 73 & $23-228$ & 42 & $12-105$ & 0.4 & nd-0.9 & 171 & $1.7-524$ \\
\hline$\sum$ Decs & 148 & 69-303 & 352 & $116-885$ & 342 & $109-1139$ & 1.7 & $0.2-3.7$ & 334 & $40-598$ \\
\hline
\end{tabular}

nd: not detected. 
$\sum$ Decs in surface sediment ranged from 116 to $885 \mathrm{pg} / \mathrm{g}$. Dec 603, Dec 604, and both DP isomers (syn- and anti-DP) were detected in all samples from King's Bay, with mean concentrations of $1.5,7.9,270$, and 73 pg/g, respectively. Dec 602 was detected in only $88 \%$ of sediment samples. Dec 602, Dec 603, Dec 604, and DP were detected in all surface sediment samples from the Great Lakes, in which their concentrations ranged from 0.001 to 11 , from 0.001 to 0.6 , and from 0.001 to $8 \mathrm{ng} / \mathrm{g}$ dry weight (dw), respectively (Shen et al., 2010). Concentrations in surface sediments from various locations in China were also measured in previous studies. The concentrations are as follows: Dalian, $3 \mathrm{ng} / \mathrm{g} d w$ (Jia et al., 2011); Harbin, 0.12 (Ma et al., 2011) and 0.05 ng/g dw (Qi et al., 2010); and Huai'an, from 2 to 8 ng/g dw (Wang et al., 2010b). These levels of Decs are higher than the values obtained in this study.

The concentrations of Decs in surface seawater and sediment are shown in Fig. 2. The highest concentrations of seawater samples were observed at station $\mathrm{K} 1$ in the inlet of the bay. By contrast, station $\mathrm{K} 6$, which is located in the interior of the bay, presented comparatively low concentrations, with the concentrations of surface sediment being the highest in this station. Glacial melt water and freshwater input are probably the major reasons that led to the aforementioned phenomenon in seawater samples. The distribution status of the surface sediment is incongruent with the status of the surface seawater. This condition may be related to the depositional characteristic of Decs. The content of organic carbon is relatively high, thus leading to high concentrations of Decs at station K6. However, conducting further study along King's Bay may provide detailed information on DP sources and possible alterations of the mean ratios of anti-DP to total DP ( $\left.f_{\text {anti }}\right)$ during long-range atmospheric transport to the Arctic.

\subsubsection{Soil, moss, and dung}

Soil is considered a major sink of Decs. The former receives the latter mainly from dry/wet deposition of particles and litter fall. In this study, Dec 602 and Dec 603 were measured in over $80 \%$ of soil samples acquired from Ny-Ålesund. The concentrations of Dec 602 and Dec 603 ranged from nd (not detected) to 2.8 and nd to $8.6 \mathrm{pg} / \mathrm{g}$, respectively. In previous works, the concentrations of Decs have been mostly measured in soil samples from Asia, in which investigations have focused on areas neighboring Decs factories and urban areas. The findings of these previous works are as follows: Huai'an, $63.5 \mathrm{ng} / \mathrm{g}$ (Wang et al., 2010a) and Harbin, $11.3 \mathrm{ng} / \mathrm{g}$ (Ma et al., 2011). The DP levels in Ny-Ålesund were two orders lower than those in the aforementioned places.

Plants have an important role in removing some contaminants from the atmosphere. Among all types of vegetation, moss and pine needles are currently used as typical, natural passive air samplers to indicate atmospheric pollution (Chen et al., 2006; Liu et al., 2005). At present, minimal or no information on Decs levels in plants has been reported. Moss from Ny-Ålesund was measured in this study. The total Decs concentrations in moss ranged from 0.2 to $3.7 \mathrm{pg} / \mathrm{g}$ (with a mean value of $1.7 \mathrm{pg} / \mathrm{g}$ ). Dec 602 was not detected in moss samples. However, DP (syn- and anti-DP) was measured in all samples. Dec 603 and Dec 604 were detected in 25\% and $87 \%$, respectively, of all samples.

According to the gathered information, most reports have only focused on humans, or on aquatic and terrestrial biota.

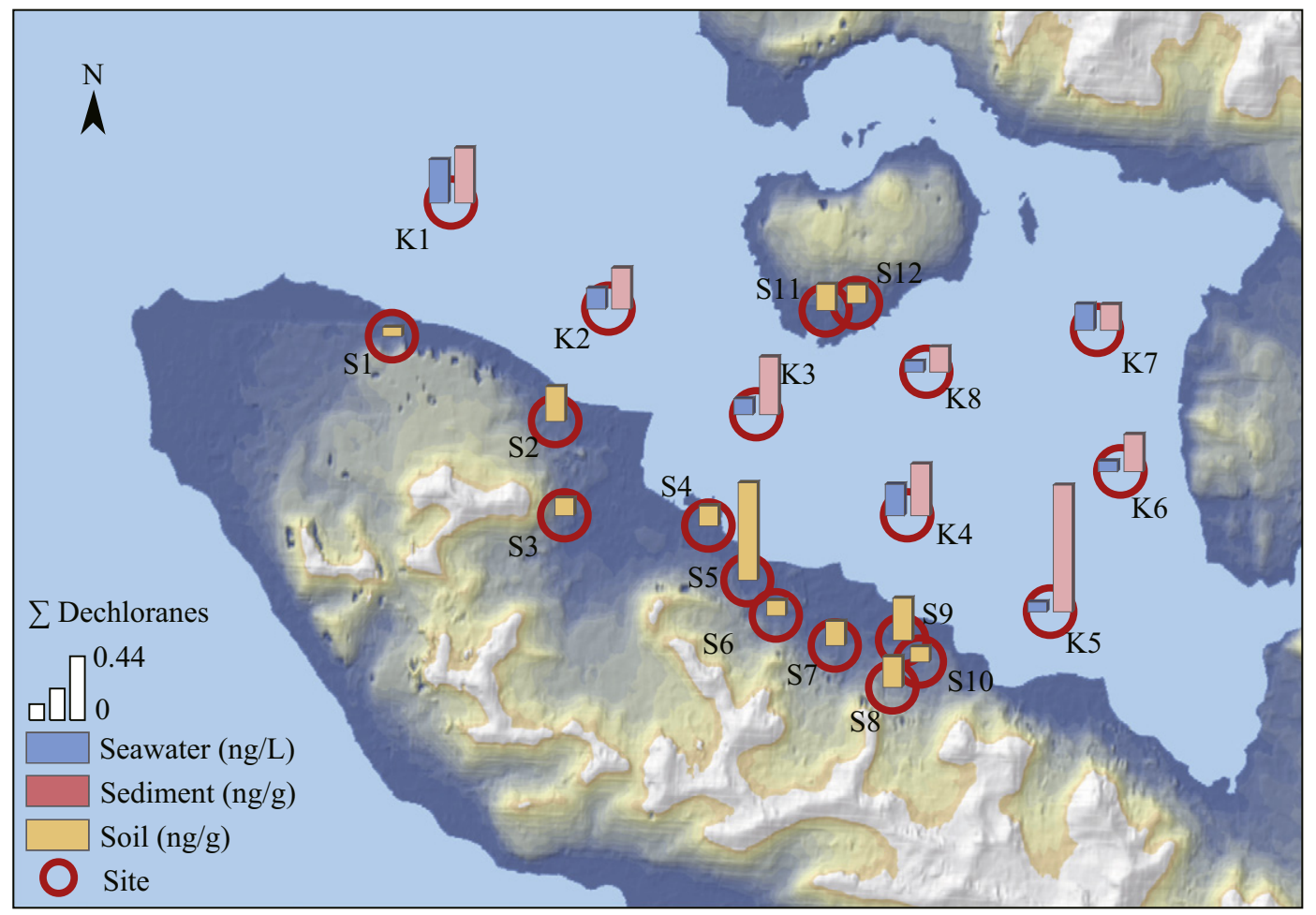

Fig. 2 - Concentrations of Decs in surface seawater, sediment and soil. 


\begin{tabular}{|c|c|}
\hline Matrices & $f_{\text {anti }}$ \\
\hline Seawater & 0.36 \\
\hline Sediment & 0.21 \\
\hline Soil & 0.18 \\
\hline Moss & 0.27 \\
\hline Reindeer dung & 0.66 \\
\hline Bird dung & 0.67 \\
\hline Gas & 0.43 \\
\hline Commercial DP & $0.65-0.80$ \\
\hline
\end{tabular}

No reference for the levels of Decs in organism dung has been produced. In the present research, 5 Decs were detected in most samples. The total concentrations of Decs in dung samples ranged from 40 to $598 \mathrm{pg} / \mathrm{g}$ (with a mean value of $334 \mathrm{pg} / \mathrm{g}$ ). DPs (syn- and anti-DP) that ranged from 5 to $722 \mathrm{pg} / \mathrm{g}$ were predominantly identified in 5 Decs, with a mean value of $258 \mathrm{pg} / \mathrm{g}$.

The difference in Decs distribution in soil, moss, and dung (reindeer and bird dung) may be related to the physicochemical properties of individual Decs and different accumulation routes of Decs in the three compartments. As stated earlier, soil accumulates Decs mainly through the dry/wet deposition of particles, moss acquires Decs mainly from the vapor phase, and dung gathers Decs mainly through the migration behavior of reindeer and birds. Soil and dung are expected to accumulate more Decs than moss.

The findings of this research clearly showed lower concentrations of Decs in moss than in other media. Decs were detected in all matrices, with higher concentrations in soil and sediment. The concentrations of Decs in Ny-Ålesund were lower than those in European and Asian regions. Low levels of human activities and relatively mild atmospheric pollution are significant factors in the low concentration of Decs in Ny-Ålesund.

\subsection{Source analysis of DP}

The transport behavior of persistent organic pollutions can be characterized as "local" and "global" (Tanabe, 2007). As a kind of persistent organic pollutant, the sources of DP should be divided into local and global sources. Recently, the ratio of its two stereo isomers has been frequently discussed in the environmental fate and source analysis of DP. The $f_{\text {anti }}$ value is defined as the concentration of anti-DP divided by the sum of the concentrations of syn- and anti-DP. The $f_{\text {anti }}$ value was reported for DP commercial products, ranging from 0.65 to 0.8 (Hoh et al., 2006; Tomy et al., 2007; Wang et al., 2010b). In the source regions such as the Jiangsu Province of China (Wang et al., 2010a) and the Great Lakes area of North America (Sverko et al., 2010; Hoh et al., 2006), the ratios of the two isomers in various matrices were close to the value of DP commercial products. However, the $f_{\text {anti }}$ values in air samples collected along the Atlantic transect (England-Spain-west-Africa-Antarctica) ranged from 0.63 to 0.3 , and the values for samples from the southern Atlantic Ocean were all about 0.35; most of these values were significantly lower than that of the commercial product, and showed a stereoselective depletion of anti-DP likely caused by UV-sunlight during long range atmospheric transport (Möller et al., 2010). In the same research, the mean $f_{\text {anti }}$ values in seawater samples were reported as 0.47 for the East Greenland Sea and 0.35 for the Atlantic transect; the values were similar to $f_{\text {anti }}$ values in the atmosphere in the same region as a result of atmospheric dry deposition.

In this study, the isomer ratios of DP in multi-matrices are summarized in Table 2 . The mean values of $f_{\text {anti }}$ are $0.36,0.21$, $0.18,0.27,0.66$, and 0.43 in surface seawater, sediment, soil, moss, dung, and atmospheric samples, respectively. The mean $f_{\text {anti }}$ value in atmospheric samples was 0.43 , significantly lower than that of the commercial product (0.65). Moreover, the mean $f_{\text {anti }}$ value in surface seawater was similar to the $f_{\text {anti }}$ value in atmospheric samples in the same region, as a probable result of atmospheric dry deposition. The values in air and seawater samples were similar to those in the Atlantic transect reported by Möller et al. (2010). This indicated that long range atmospheric transport was the main pathway for DP transport into remote areas. It was reported that the $f_{\text {anti }}$ values in sediments were higher than or equal to that in DP commercial products in the Great Lakes (Qiu et al., 2007), the reason may be that the study area is close to the manufacturer of DP, thus the transport pathway belongs to the category of "local" pollutant. However, there is no manufacturer of DP at Ny-Ålesund in the Arctic, yet DP isomers were detected, this indicated that long range transport is the main source in the Arctic as previously reported. The mean $f_{\text {anti }}$ values in sediment and soil were a bit lower than those in the atmosphere of Ny-Ålesund. This indicated that long range atmospheric transport may be the main source of DP, and the changes in isomer ratio were likely a result of different degrees of isomer photo-degradation and micro-organism degradation in transport and deposition processes. However, the dung value of $f_{\text {anti }}$ was significantly different from that of the other matrices. The $f_{\text {anti }}$ value in dung (0.66 in reindeer dung and 0.67 in bird dung) was close to the value in commercial products (0.65). DP in dung may be classified as a "local" pollutant because of the migration behavior of reindeer and birds, according to the aforementioned analysis. Furthermore, bioaccumulation/biotransformation in organisms may also lead to the higher isomer ratio in dung than in the other matrices. Therefore, more research is needed to investigate the DP transport pathways and bioaccumulation behaviors in organisms.

\section{Conclusions}

Currently available information shows that Decs have become a global environmental contaminant, not only in Asian and European regions, but also in the polar areas and the Qinghai-Tibet Plateau, in which no source of pollution was identified. This finding suggests that Decs have the capability for long-range atmospheric transport. The concentrations of Decs in multi-matrices at Ny-Ålesund in the Arctic are evidently lower than those in Asian and European regions. The concentrations of Decs in surface seawater from the inlet of King's Bay are higher than those in the interior of the bay. This condition is probably caused by glacial melt water and 
freshwater input, and more research is needed to confirm this. The fraction of anti-DP in the atmosphere, soil and sediment and dung indicated that the main source of DP in Ny-Ålesund was long-range atmospheric transport, and the migration behavior of reindeer and birds may be another source.

\section{Acknowledgments}

The research was supported by the National Natural Science Foundation of China (No. 21377032), the Chinese Polar Environment Comprehensive Investigation and Assessment Program (Nos. 2014-02-01, 2014-03-04, 2014-04-01, 2014-04-03), the Marine Public Welfare Scientific Research Projects (No. 201105013) and the Foundation of Polar Science Key Laboratory, SOA, China (No. KP201208).

\section{R E F E R E N C E S}

Betts, K.S., Cooney, C.M., Renner, R., Thrall, L., 2006. A new flame retardant in the air. Environ. Sci. Technol. 40 (4), 1090-1091.

Chanada, M., Roy, S.K., 2007. Plastics Technology Handbook, 4th ed.

Chen, J.W., Zhao, H.M., Gao, L.N., Henkelmann, B., Schramm, K.W., 2006. Atmospheric PCDD/F and PCB levels implicated by pine (Cedrus deodara) needles at Dalian, China. Environ. Pollut. 144 (2), 510-515.

Chen, S.J., Tian, M., Wang, J., Shi, T., Luo, Y., Luo, X.J., et al., 2011. Dechlorane Plus (DP) in air and plants at an electronic waste (e-waste) site in South China. Environ. Pollut. 159 (5), 1290-1296.

Feo, M.L., Barón, E., Eljarrat, E., Barceló, D., 2012. Dechlorane Plus and related compounds in aquatic and terrestrial biota: a review. Anal. Bioanal. Chem. 404 (9), 2625-2637.

Guerra, P., Fernie, K., Jiménez, B., 2011. Dechlorane plus and related compounds in peregrine falcon (Falco peregrinus) eggs from Canada and Spain. Environ. Sci. Technol. 45 (4), 1284-1290.

Hoh, E., Zhu, L.Y., Hites, R.A., 2006. Dechlorane plus, a chlorinated flame retardant, in the Great Lakes. Environ. Sci. Technol. 40 (4), 1184-1189.

INCHEM, 2010. International programme on chemical safety. 44 (Mirex; http://www.inchem.org/documents/ehc/ehc/ehc44. htm).

Jia, H.L., Liu, Y.Q., Yang, M., 2011. Concentration and bioaccumulation of dechlorane compounds in coastal environment of Northern China. Environ. Sci. Technol. 45 (7), 2613-2618.

Liu, X., Zhang, G., Jones, K.C., Li, X.D., Peng, X.Z., Qi, S.H., 2005. Compositional fractionation of polycyclic aromatic hydrocarbons (PAHs) in mosses (Hypnum plumaeformae WILS.) from the northern slope of Nanling Mountains, South China. Atmos. Environ. 39 (30), 5490-5499.

Ma, W.L., Liu, L.Y., Qi, H., Sun, D.Z., Shen, J.M., Wang, D.G., et al., 2011. Dechlorane plus in multimedia in northeastern Chinese urban region. Environ. Int. 37 (1), 66-70.

MatWeb, 2009. Material Safety Data Sheet: Molykote®. AS-810. Dow Corning Corporation, Midland MI.

Milne, G.W.A., 2005. Gardner's Commercially Important Chemicals: Synonyms, Trade Names, and Properties, 11th ed. Hoboken, NJ, John Wiley \& Sons, Inc.
Möller, A., Xie, Z.Y., Sturm, R., Ebinghaus, R., 2010. Large-scale distribution of dechlorane plus in air and seawater from the Arctic to Antarctica. Environ. Sci. Technol. 44 (23), 8977-8982.

NTP, 1990. National toxicology program, NTP TR 313. Toxicology and Carcinogenesis Studies of Mirex. US Department of Health and Human Services, Greensboro.

Qi, H., Liu, L.Y., Jia, H.L., Li, Y.F., Ren, N.Q., You, H., et al., 2010. Dechlorane plus in surficial water and sediment in a Northeastern Chinese River. Environ. Sci. Technol. 44 (7), 2305-2308.

Qiu, X.H., Hites, R.A., 2008. Dechlorane Plus and other flame retardants in tree bark from the Northeastern United States. Environ. Sci. Technol. 42 (1), 31-36.

Qiu, X.H., Marvin, C.H., Hites, R.A., 2007. Dechlorane plus and other flame retardants in a sediment core from Lake Ontario. Environ. Sci. Technol. 41 (17), 6014-6019.

Ren, N.Q., Sverko, E., Li, Y.F., Zhang, Z., Harner, T., Wang, D.G., et al., 2008. Levels and isomer profiles of dechlorane plus in Chinese air. Environ. Sci. Technol. 42 (17), 6476-6480.

Ren, G.F., Yu, Z.Q., Ma, S.T., Li, H.R., Peng, P.G., Sheng, G.Y., et al., 2009. Determination of dechlorane plus in serum from electronics dismantling workers in South China. Environ. Sci. Technol. 43 (24), 9453-9457.

Shen, L., Reiner, E.J., Macpherson, K.A., Kolic, T.M., Sverko, E., Helm, P.A., et al., 2010. Identification and screening analysis of halogenated norbornene flame retardants in the Laurentian Great Lakes: Dechloranes 602, 603, and 604. Environ. Sci. Technol. 44 (2), 760-766.

Sverko, E., Reiner, E.J., Tomy, G.T., McCrindle, R., Shen, L., Arsenault, G., et al., 2010. Compounds structurally related to dechlorane plus in sediment and biota from Lake Ontario (Canada). Environ. Sci. Technol. 44 (2), 574-579.

Tanabe, S., 2007. Contamination by persistent toxic substances (PTS) in the Asia-Pacific Region. Dev. Environ. Sci. 7, 773-817.

Tomy, G.T., Pleskach, K., Ismail, N., 2007. Isomers of dechlorane plus in Lake Winnipeg and Lake Ontario food webs. Environ. Sci. Technol. 41 (7), 2249-2254.

Venier, M., Hites, R.A., Whittle, D., Michael, H.P.A., Sverko, E., et al., 2008. Flame retardants in the atmosphere near the Great Lakes. Environ. Sci. Technol. 42 (13), 4745-4751.

Wang, B., Iino, F., Huang, J., Lu, Y., Yu, G., Morita, M., 2010a. Dechlorane Plus pollution and inventory in soil of Huai'an City, China. Chemosphere 80 (11), 1285-1290.

Wang, D.G., Yang, M., Qi, H., Sverko, E., Ma, W.L., Li, Y.F., 2010b. An Asia-specific source of dechlorane plus: concentration, isomer profiles, and other related compounds. Environ. Sci. Technol. 44 (17), 6608-6613.

Wu, J.P., Zhang, Y., Chen, X.J., Wang, J., Chen, S.J., Guan, Y.T., et al., 2010. Isomer-specific bioaccumulation and trophic transfer of dechlorane plus in the freshwater food web from a highly contaminated site, South China. Environ. Sci. Technol. 44 (2), 606-611.

Xian, Q.M., Siddique, S., Li, T., Feng, Y.L., Takser, L., Zhu, J.P., 2011. Sources and environmental behavior of dechlorane plus-a review. Environ. Int. 37 (7), 1273-1284.

Zhang, X.L., Luo, X.J., Liu, H.Y., Yu, L.H., Chen, S.J., Mai, B.X., 2011. Bioaccumulation of several brominated flame retardants and dechlorane plus in waterbirds from an E-waste recycling region in South China: associated with trophic level and diet sources. Environ. Sci. Technol. 45 (2), 400-405.

Zhu, J.P., Peng, Y.L., Shoeib, M., 2007. Detection of dechlorane plus in residential indoor dust in the city of Ottawa, Canada. Environ. Sci. Technol. 41 (22), 7694-7698. 